\title{
Problems of problem-based learning: Towards transformative critical pedagogy in medical education
}

\author{
Alice Cavanagh ${ }^{1,2} \cdot$ Meredith Vanstone ${ }^{3,4} \cdot$ Stacey Ritz ${ }^{5,6}$
}

Published online: 10 January 2019

(c) The Author(s) 2019

\begin{abstract}
Problem-based medical education is based in a biomedical worldview that works to entrench deterministic ways of thinking about socioculturally-influenced health disparities in the minds of medical trainees. This perspective paper considers the utility of Paolo Freire's critical pedagogy as a means of redressing this issue, as it may enable medical learners to perceive and address the social sources of illness that shape their patients' lives. With an eye to advancing health equity, and educating health professionals who are responsive to marginalized and vulnerable communities, this paper considers how a problem-posing medical education could redefine physicians' relationships to knowledge, identity, and to their patients.
\end{abstract}

Keywords Critical pedagogy $\cdot$ Problem-based learning $\cdot$ Undergraduate medical education

Calls to address health inequity through medical practice have spurred a search for new approaches to professional training with the potential to shift medical practice closer to the humane, political, social medicine described by Virchow in the nineteenth century [1]. These efforts have achieved limited success: although 'health advocacy' has been recognized as a core competency for medical learners [2-4], the scope of responsibilities attached to this role remain unclear to educators and trainees $[5,6]$; although

Previous Presentations: A paper based on this work was given at the MacPherson Institute's Annual Research on Teaching \& Learning Conference at McMaster University in Hamilton, Ontario in October 2017; a poster based on this work was presented at The Canadian Conference on Medical Education in Halifax, Nova Scotia in April 2018.

Alice Cavanagh

cavanaam@mcmaster.ca

1 Health Policy PhD Program, McMaster University, Hamilton, ON, Canada

2 Michael G. DeGroote School of Medicine, McMaster University, Hamilton, ON, Canada

3 Department of Family Medicine, McMaster University, Hamilton, ON, Canada

4 McMaster Program for Education Research, Innovation \& Theory (MERIT), Hamilton, ON, Canada

5 Department of Pathology and Molecular Medicine, McMaster University, Hamilton, ON, Canada

6 Medical Sciences Division, Northern Ontario School of Medicine, Sudbury, ON, Canada commitments to social accountability are common in medical schools' formal mandates [7], medical students are taught to be 'aware' of health disparities without understanding political realities that give rise to them [8]. While perspectives from critical pedagogy have not made significant inroads in medical education, we argue that Paolo Freire's model of problem-posing education has much to offer contemporary medical educators. Acknowledging the influence of sociocultural, political, and environmental determinants on human health, Freire's critical pedagogy could represent a pivotal intervention in efforts to engage trainees in using their emergent professional power in service of social justice.

\section{Introducing the 'Pedagogy of the Oppressed'}

Fifty years after its initial publication, Freire's Pedagogy of the Oppressed remains a vital force in contemporary education. At the heart of Freire's work lies a radical proposition: education must become a 'practice of freedom' that develops 'critical consciousness' amongst its learners [9]. For Freire, this means rejecting the discipline and rote memorization that characterize conventional 'banking' approaches to education, in which teachers didactically 'deposit' knowledge into the minds of their students. Instead, Freire imagines a 'problem-posing education' (PPE) that asks students to engage in self-directed inquiry, exploring conditions responsible for social inequities [9]. To this end, Freire imagines classrooms that upend traditional hierar- 
chies, where students and teachers 'teach each other, mediated by the world' [9]. According to Freire, this egalitarian reconfiguration helps learners dispel the perception that they are isolated from their communities, or are unable to effect change; rather, students come to view themselves as capable agents of learning and action, holding a share of responsibility for the fate of their communities [9].

Although Pedagogy of the Oppressed has resonated with scholars over decades, critics have long argued that Freire's focus on poverty works to obscure other types of oppression that can result in poor health outcomes [10-12]. In Teaching to Transgress, bell hooks suggests that educators can address this deficit by directing students to interrogate the overlapping aspects of their identity that shape their passage through the world [13-16]. We contend that this reinterpretation of Freire's work has much to offer medical educators and learners: akin to the banking model described by Freire, medical education has long been charged with tacitly socializing students to stress patients' personal responsibility for poor health, without acknowledging the social contexts that shape their 'lifestyle choices' $[17,18]$. We are aware that implementing Freire's 'pedagogy of the oppressed' for a social group as privileged as trainee-physicians may have its own challenges [19-21]. However, by asking medical students to think critically about social patterns of professional exclusion and the structural causes of ill health, we see fertile opportunities for fostering learners' critically reflexive commitments to professional advocacy.

\section{Problem-based and problem-posing pedagogies for medical education}

Freire's problem-posing approach to education was not the only radical intervention in education to emerge during the late 1960s. First implemented at McMaster University in 1969 [22], the problem-based learning (PBL) model for medical education emerged as an answer to the accelerating pace of innovation in healthcare. Advocates for PBL argued that structuring medical learning around unique, progressing case studies prepared new physicians 'to keep up with changing concepts and new knowledge' [23], developing skills for self-directed research and life-long learning. Fifty years later, problem-based curricula have been implemented in training programs for healthcare providers worldwide [24-26]. Meta-analyses and systematic reviews plentifully support PBL as a model for medical education [22, 27, 28], and the competence of graduates of problem-based medical programs is comparable to their conventionally trained colleagues [29]. Problem-based pedagogies have been credited with training physicians who are better critical thinkers [30], more effective working in teams [31], and more at- tuned to public health concerns that arise in their clinical practice [32].

PBL and Freire's PPE share more than a passing resemblance: both pedagogies renounce student passivity and position responsive, self-directed inquiry at the heart of their curricula; both pedagogies reject lecture-based content delivery, and re-imagine the role of teachers as supportive facilitators of learners' exploration. In instrumental ways, however, the two approaches diverge, resulting in profoundly different implications for medical education. Below, we offer three examples comparing problem-posing and problem-based approaches to medical learning that illustrate the value of incorporating Freire's pedagogy into medical education.

\section{Example one: reconceptualizing problems}

One central point of divergence between PBL and PPE lies in how each model conceptualizes the 'problems' at the heart of each pedagogy [33]. Week-to-week in PBL, problems come in the form of short case vignettes, briefly sketching the story of a presenting patient and their medical history. These case-studies serve a dual purpose, prompting students to set medical knowledge learning objectives in order to understand each case while enlisting them into a 'cognitive apprenticeship' that acculturates them 'into the thinking practices of medicine' [34]. This framing - of individual patients as biomedical problems, largely abstracted from their family or life circumstances_-by definition casts trainee-physicians in the role of problem-solvers. Although PBL destabilizes the hierarchy between learners and teachers, it does little to problematize how the power of professional authority shapes the clinical encounter or the narrow capacity of allopathic medical interventions to address structural causes of ill-health [35]. By contrast, in a PPE approach to medical learning, students would be tasked with problematizing political contexts that give rise to population health disparities, and learning about collaborative approaches to patient care [33]. Through PPE, the role of care provider could be reconfigured from that of 'most responsible problem-solver' to one of multiple situated actors with insight and agency, promoting collaborative engagement with patients [35].

In a case study featuring a diabetic patient who is 'nonadherent' to treatment, for instance, PPE tutors would help students interrogate social contexts shaping patients' follow-through with prescribed treatment regimens, in addition to biomedical implications of poor glycaemic control $[36,37]$. Asked to explore how their professional and personal identities shape clinical encounters, students would also be encouraged to forge habits of reflexive practice that last throughout their careers [38]. Practised in critiquing 
the origins, omissions and implications of medical epistemology from their earliest days of training, PPE-trained physicians would graduate medical school well-equipped to identify the origins of ill-health in their communities and to advocate for policy change.

\section{Example two: reconceptualizing knowledge}

Another point of tension between PPE and PBL lies in the relationship each understands between knowledge and the knower. In PBL, students learn foundational medical knowledge through self-directed research [23], using principles of evidence-based medicine (EBM) in their evaluation of sources [39]. Although PBL has been lauded for its utility teaching critical research appraisal and responsive inquiry [39], it does not encourage students to think critically about assumptions of objectivity and generalizability that support the supremacy of scientific knowledge over other ways of approaching health problems [40]. In Pedagogy of the Oppressed, Freire presages this critique, writing that science becomes an instrument of oppression when its internal logics - the basis for its authority-are obscured as 'unquestionably powerful' [9]. In EBM, after aggregated studies are ranked according to hierarchies of value, research findings are reformulated as guidelines for broad application in the clinical context; through this process, biomedical 'fact' is alienated from the circumstances in which it was generated. Scientific knowledge becomes sedimented, and increasingly resistant to challenge through the compounded force of its scientific authority [40]. Later, when medical learners are asked to research cases relying only on sanctioned sources of knowledge, facets of human experience that are not accounted for in biomedical inquiry may be invisible to these learners.

Randomized controlled trials of treatment for depression that exclude gender-based analyses offer one example of this phenomenon at work: research can meet methodological criteria to be deemed 'high quality' according to the principles of EBM, while still obscuring gendered differences in depression symptomatology and treatment effects that have profound implications for clinical practice [41]. In PPE, therefore, students would be tasked with considering the social and political implications of how biomedical knowledge is constructed, including the legacies of medical sexism, racism and ableism entrenched in historical and contemporary medical research practices $[42,43]$. Trained to consider biomedical research as socially constructed and subject to continual revision even as they use it in their practice, graduates of problem-posing medical training would be well-equipped to develop research agendas that account for knowledge as a form of power and that harness that power in service of social justice.

\section{Example three: reconceptualizing patients}

A final point of difference between PBL and PPE lies in the use of social determinants of health frameworks to understand the lives and ill-health of patients at the heart of medicine. In PBL, the social determinants of health are often invoked to encourage students to consider how a patient's individual characteristics might be shaping their illness $[16,44]$. Although this analysis affords students an opportunity to consider the epidemiology of illness and how it aligns with positions of social inequity, case descriptions meant to inspire these conversations fall well short of matching the appreciable texture of real patients' social identities. MacLeod's analysis of a second year PBL medical curriculum, for instance, found that cases seldom articulated the race of patients unless the stated medical learning objectives were directly linked to racialized genetic risk factors for illnesses such as sickle cell anaemia or Tay-Sachs disease [45]. This approach leaves students with little opportunity to explore harms to health borne of racism, marginalization, and lack of access to culturally relevant healthcare services. The absence of thoughtfulness about these identity features fuels assumptions that embodied health inequities are trans-historical or biologically inevitable rather than fluid, evolving, and forged by oppressive politically imposed structures [44]. Underscoring all this lies the reality that when PBL students are tasked with deciphering a case, understanding the social context of illness often falls second to mastering biomedical learning objectives. The social context becomes something to 'recognize' or 'acknowledge' as opposed to a site of possible professional intervention or advocacy.

By contrast, students in PPE classrooms would be encouraged to probe the structural causes of ill health they see embodied in the clinic, questioning how their professional and personal roles, as well socio-political structures, are implicated in upholding these disparities in health. Students would be tasked with developing a richer understanding of how lived experiences of race, gender, migration status and other facets of social identity combine to affect their patients. Ultimately, students in a PPE classroom would challenge deterministic conceptions of health, coming to see their whole social reality as contingent-a site of activist intervention, in solidarity with the sickest in society.

\section{Moving towards a problem-posing medical education}

While decades of research have established some of its benefits, PBL remains enmeshed in a biomedical healthcare system that maintains deterministic conceptions of health inequity and social injustice; here, we have advanced a vi- 
sion of a problem-posing medical pedagogy that broadens the scope of PBL, training physicians who are actively engaged in dismantling oppressive social structures that make their patients sick. To achieve this end, students of PPE would be asked to complicate their relationships to biomedical knowledge, reconsider hierarchical dynamics in the clinic, and re-centre the struggle against social causes of illness at the heart of their future practices of medicine and medical research. Although Freire's pedagogy remains beyond the boundaries of medical education as it is imagined today, pressing challenges to human health make the embrace of this-and other-transformational pedagogies both needed and necessary.

Open Access This article is distributed under the terms of the Creative Commons Attribution 4.0 International License (http:// creativecommons.org/licenses/by/4.0/), which permits unrestricted use, distribution, and reproduction in any medium, provided you give appropriate credit to the original author(s) and the source, provide a link to the Creative Commons license, and indicate if changes were made.

\section{References}

1. Whitehead CR, Hodges BD, Austin Z. Captive on a carousel: discourses of 'new' in medical education 1910-2010. Adv Health Sci Educ Theory Pract. IEEE Trans Med Imaging. 2013;18:755:68.

2. Dobson S, Voyer S, Hubinette M, Regehr G. From the clinic to the community: the activities and abilities of effective health advocates. Acad Med. 2015;90:214-20.

3. Bhate TD, Loh LC. Building a generation of physician advocates: the case for including mandatory training in advocacy in Canadian Medical School Curricula. Acad Med. 2015;90:1602-6.

4. Frank J, Snell L, Sherbino J. CanMEDS. ON, Vol. 2015. Ottawa: Physician Competency Framework; 2015.

5. Hubinette M, Dobson S, Towle A, Whitehead C. Shifts in the interpretation of health advocacy: a textual analysis. Med Educ. 2014;48:1235-43.

6. Dharamsi S, Ho A, Spadafora SM, Woollard R. The physician as health advocate: translating the quest for social responsibility into medical education and practice. Acad Med. 2011;86:1108-13.

7. Ritz S, Beatty K, Ellaway R. Accounting for social accountability: Developing critiques of social accountability within medical education. Educ Health. IEEE Trans Med Imaging. 2014;27:152:7.

8. Sharma M, Pinto AD, Kumagai AK. Teaching the Social Determinants of Health: A Path to Equity or a Road to Nowhere? Acad Med. 2018;93:25-30.

9. Freire P. Pedagogia do Oprimido. New York, NY: Continuum International Publishing Group; 2005.

10. Maher FA. Toward a richer theory of feminist pedagogy: A comparison of 'liberation' and 'gender' models for teaching and learning. J Educ Res. 1987;169:91-100.

11. Weiler K. Freire and a Feminist Pedagogy of Difference. Harv Educ Rev. IEEE Trans Med Imaging. 1991;61:449:75.

12. Brady J. Critical literacy, feminism, and a politics of representation. The Politics of Liberation. New York: Routledge; 2002. pp. 162-73.

13. Rancière J. The emancipated spectator. New York, NY: Verso Books; 2014.

14. Ellsworth E. Why doesn't this feel empowering? Working through the repressive myths of critical pedagogy. Harv Educ Rev. IEEE Trans Med Imaging. 1989;59:297:325.
15. Hooks B. Teaching To Transgress: Education as Practice of Freedom. New York, NY: Routledge; 1994.

16. Crenshaw K. Mapping the Margins: Intersectionality, Identity Politics, and Violence against Women of Color. Stanf Law Rev. IEEE Trans Med Imaging. 1991;43:1241:99.

17. Hafferty FW, Franks R. The hidden curriculum, ethics teaching, and the structure of medical education. Acad Med. 1994;69:861-71.

18. Waitzkin H. A Critical Theory of Medical Discourse: Ideology, Social Control, and the Processing of Social Context in Medical Encounters. J Health Soc Behav. 1989;30:220-39.

19. Saha S, Guiton G, Wimmers PF, Wilkerson L. Student body racial and ethnic composition and diversity-related outcomes in US medical schools. JAMA. 2008;300:1135-45.

20. Young ME, Razack S, Hanson MD, et al. Calling for a broader conceptualization of diversity: surface and deep diversity in four Canadian medical schools. Acad Med. 2012;87:1501-10.

21. Southgate E, Kelly BJ, Symonds IM. Disadvantage and the 'capacity to aspire' to medical school. Med Educ. 2015;49:73-83.

22. Neville AJ. Problem-Based Learning and Medical Education Forty Years On. Med Princ Pract. 2009;18:1-9.

23. Neufeld VR, Barrows HS. The 'McMaster Philosophy': an approach to medical education. Acad Med. 1974;49:1040-50.

24. Iputo JE, Kwizera E. Problem-based learning improves the academic performance of medical students in South Africa. Med Educ. 2005;39:388-93.

25. Yuan H. Kunaviktiku IW, Klunklin A, Williams BA. Improvement of nursing students' critical thinking skills through problem-based learning in the People's Republic of China: A quasi-experimental study. Nurs Health Sci. 2008;10:70-6.

26. Mesquita AR, Souza WM, Boaventura TC, et al. The Effect of Active Learning Methodologies on the Teaching of Pharmaceutical Care in a Brazilian Pharmacy Faculty. PLoS ONE. 2015;10. https:// doi.org/10.1371/journal.pone.0123141

27. Vernon DT, Blake RL. Does problem-based learning work? A metaanalysis of evaluative research. Acad Med. 1993;68:550-63.

28. Thistlethwaite JE, Davies D, Ekeocha S, et al. The effectiveness of case-based learning in health professional education. A BEME systematic review: BEME Guide. Med Teach. 2012;34(23):e421-e44.

29. Koh GC-H, Khoo HE, Wong ML, Koh D. The effects of problembased learning during medical school on physician competency: a systematic review. Can Med Assoc J. 2008;178:34-41.

30. Tiwari A, Lai P, So M, Yuen K. A comparison of the effects of problem-based learning and lecturing on the development of students' critical thinking. Med Educ. 2006;40:547-54.

31. Norman GR, Schmidt HG. Effectiveness of problem-based learning curricula: theory, practice and paper darts. Med Educ. 2000;34: 721-8.

32. Gurpinar E, Musal B, Aksakoglu G, Ucku R. Comparison of knowledge scores of medical students in problem-based learning and traditional curriculum on public health topics. Bmc Med Educ. 2005;5:7.

33. DasGupta S, Fornari A, Geer K, et al. Medical Education for Social Justice: Paulo Freire Revisited. J Med Humanit. 2006;27:245-51.

34. Hmelo-Silver CE, Barrows HS. Goals and strategies of a problem-based learning facilitator. IJPBL. IEEE Trans Med Imaging. 2006;1:4.

35. Fenwick T, Parsons J. Boldly solving the world: a critical analysis of problem-based learning as a method of professional education. Stud Educ Adults. IEEE Trans Med Imaging. 1998;30:53:66.

36. Broyles LM, Colbert AM, Erlen JA. Medication practice and feminist thought: A theoretical and ethical response to adherence in HIV/AIDS. Bioethics. 2005;19:362-78.

37. Sjöström S. Invocation of coercion context in compliance communication-power dynamics in psychiatric care. Int $\mathrm{J}$ Law Psychiatry. 2006;29:36-47. 
38. Ng SL, Kinsella EA, Friesen F, Hodges B. Reclaiming a theoretical orientation to reflection in medical education research: a critical narrative review. Med Educ. 2015;49:461-75.

39. Lusardi MM, Levangie PK, Fein BD. A Problem-Based Learning Approach to Facilitate Evidence-Based Practice in Entry-Level Health Professional Education. J Prosthet Orthot. 2002;14:40-50.

40. Goldenberg MJ. On evidence and evidence-based medicine: Lessons from the philosophy of science. Soc Sci Med. 2006;62: 2621-32.

41. Weinberger AH, McKee SA, Mazure CM. Inclusion of Women and Gender-Specific Analyses in Randomized Clinical Trials of Treatments for Depression. J Womens Health. IEEE Trans Med Imaging. 2010;19:1727-32.

42. Knorr Cetina K. Epistemic cultures: How the sciences make knowledge. Cambridge, Massachusetts: Harvard University Press; 1999.

43. Washington HA. Medical apartheid: The dark history of medical experimentation on Black Americans from colonial times to the present. Books: Doubleday; 2006.
44. Bowleg L. The Problem With the Phrase Women and Minorities: Intersectionality - an Important Theoretical Framework for Public Health. Am J Public Health. 2012;102:1267-73.

45. MacLeod A. Six ways problem-based learning cases can sabotage patient-centered medical education. Acad Med. 2011;86:818-25.

Alice Cavanagh is an $\mathrm{MD} / \mathrm{PhD}$ student at McMaster University, completing her doctoral work in Health Policy on the social organization and structural implications of medical education.

Meredith Vanstone is assistant professor in the Department of Family Medicine, and a scientist in the McMaster program for Education Research, Innovation \& Theory (MERIT).

Stacey Ritz is associate professor in the Department of Pathology \& Molecular Medicine, and assistant dean of the Bachelor of Health Sciences (Honours) Program. 